\title{
STRATEGI PENGELOLAAN LIMBAH DI PELABUHAN ARAR KABUPATEN SORONG YANG BERKELANJUTAN
}

\section{STRATEGY OF SUSTAINABLE WASTE MANAGEMENT IN PORT OF ARAR, SORONG}

\author{
Sehtawarta Br Sitepu ${ }^{1 *}$, Etty Riani ${ }^{2}$, dan Syaiful Anwar ${ }^{3}$ \\ ${ }^{1}$ Mahasiswa S2 Program Studi Pengelolaan Sumberdaya Alam dan Lingkungan \\ ${ }^{2}$ Departemen Managemen Sumberdaya Perairan, FPIK-IPB, Bogor \\ ${ }^{3}$ Departemen Ilmu Tanah dan Sumberdaya Lahan, Faperta-IPB, Bogor \\ *E-mail: ameyrs46@gmail.com
}

\begin{abstract}
Arar Port of Sorong is a developing port and located in an exclusive economic area. It has a potency to produce waste and higher possibility of littering. This study aims to formulate a sustainable waste management strategy at Arar Port of Sorong. In this study interviewed five expert experts selected purposively with the help of an individual questionnaire for analytical hierarchy process (AHP) purposes. The data obtained were analyzed by AHP using expert choice software 2000. The results showed that three main strategies need to be done to manage the waste in Port Arar Sorong District become sustainable. The first approach is to make the waste processing and litter into daily habituation from the community. The second strategy is to implementing zero waste technology. The last policy is enforcing the law.
\end{abstract}

Keywords: management strategy, waste, harbor, sustainable, AHP

\begin{abstract}
ABSTRAK
Pelabuhan Arar merupakan pelabuhan yang sedang berkembang dan terletak di kawasan ekonomi khusus, sehingga menghasilkan limbah dan sampah yang semakin banyak. Penelitian ini bertujuan untuk memformulasi strategi pengelolaan limbah di Pelabuhan Arar Kabupaten Sorong yang berkelanjutan. Pada penelitian ini dilakukan wawancara terhadap lima pakar ahli yang dipilih secara purposive dengan bantuan kuesioner khusus untuk keperluan analisis AHP. Data yang diperoleh dianalisis dengan analytical hierarchy process (AHP) menggunakan perangkat lunak expert choice 2000. Hasil penelitian memperlihatkan bahwa ada tiga strategi utama yang perlu dilakukan agar pengelolaan limbah di Pelabuhan Arar Kabupaten Sorong menjadi berkelanjutan, yakni membuat pengolahan limbah dan sampah menjadi satu kebiasaan dan budaya keseharian (habituasi) dari masyarakat, mencari dan menerapkan teknologi zerowaste serta melakukan penegakan hukum.
\end{abstract}

Kata kunci: strategi pengelolaan, limbah, pelabuhan, berkelanjutan, AHP

\section{PENDAHULUAN}

Indonesia merupakan negara bahari dan negara kepulauan, sehingga pelabuhan mempunyai peran yang sangat penting. Keberadaan pelabuhan tersebut meningkatkan perkembangan ekonomi, sosial, dan budaya masyarakat. Secara tidak langsung pelabuhan juga berperan dalam perkembangan pendidikan, hubungan antar bangsa dan politik, bahkan seringkali digunakan sebagai tolok ukur perkembangan suatu wilayah.
Salah satu pelabuhan yang saat ini mendapat perhatian pemerintah untuk dikembangkan adalah Pelabuhan Arar. Pelabuhan Arar terletak di sebelah selatan pelabuhan Kota Sorong, pada $1^{\circ} 1^{\prime} 41.59^{\prime \prime}$ LS dan $131^{\circ} 14^{\prime} 35.59^{\prime \prime}$ BT, yang berada di daerah administrasi Kampung Arar, Distrik Mayamuk, Kabupaten Sorong.

Pelabuhan Arar saat ini memiliki panjang $100 \mathrm{~m}$ dan hanya melayani kapal yang muatannya berupa kayu, semen, dan jenis kapal curah lainnya. Ukuran kapal rata- 
rata yang berkunjung di Pelabuhan Arar berukuran 2455 GT, memiliki panjang 83,51 $\mathrm{m}$, lebar $12,83 \mathrm{~m}$. Seperti halnya pada kegiatan antropogenik pada umumnya, aktivitas pelabuhan sudah pasti akan menghasilkan limbah. Selain hal tersebut, kapal juga merupakan salah satu penyumbang limbah di dalam laut, baik berupa limbah bahan berbahaya dan beracun (B3) maupun limbah organik mudah urai. Contoh limbah B3 yang dihasilkan dari kapal antara lain adalah oli dari kegiatan bongkar muat kapal yang bersandar di pelabuhan, ceceran bahan bakar yang digunakan oleh kapal, pembuangan air ballast, dsb. Limbah organik mudah urai di pelabuhan antara lain adalah berbagai sampah (limbah padat) yang dihasilkan dari kegiatan yang ada di kapal dan di wilayah Pelabuhan Arar itu sendiri.

Baik limbah B3 maupun limbah non B3, dalam jumlah yang melebihi kemampuan alam untuk memfurifikasi diri, apabila tidak dikelola dengan baik, maka akan membahayakan lingkungan perairan pelabuhan dan kehidupan yang ada di dalamnya (Riani, 2012). Bahkan limbah B3 seperti logam berat bukan hanya akan mengkontaminasi air dan sedimen perairan laut, namun juga dapat mengkontaminasi biota yang ada di dalamnya (Riani, 2009; 2010; 2011; Riani et al., 2017a, 2017b , dan 2017c). Oleh karena itu maka limbah-limbah tersebut harus dikelola dengan baik dan benar agar tercipta lingkungan yang baik, seperti yang dinyatakan pada Permen 101, Tahun 2014, bahwa pengelola pelabuhan harus mengelola limbah yang dihasilkan dari kegiatan pelabuhan tersebut. Oleh karena itu maka pihak pengelola Pelabuhan Arar harus membuat strategi pengelolaan limbah yang dihasilkannya.

Strategi pengelolaan limbah tersebut makin dirasa sangat diperlukan mengingat Pemerintah Kabupaten Sorong melalui Dinas Perhubungan berencana untuk melakukan perluasan dermaga sepanjang $200 \mathrm{~m}$. Oleh karena itu maka pada masa yang akan datang, Pelabuhan Arar akan dapat disandari kapal-kapal besar, sehingga dapat mengimbangi berbagai kegiatan seiring dengan ditetapkannya Kawasan Ekonomi Khusus (KEK) Arar. Pada kawasan KEK umumnya banyak industri-industri yang terbangun, Kabupaten Sorong akan berkembang menjadi kota industri, perdagangan, dan jasa. Oleh karena itu di Kabupaten Sorong bukan saja banyak industri yang terbangun, namun juga menjadi kota yang sangat strategis, baik sebagai kota persinggahan bahkan menjadi pintu keluar-masuk Provinsi Papua Barat. Hal ini akan menyebabkan semakin bertambahnya limbah yang dihasilkan, baik limbah domestik maupun Limbah B3 dari aktivitas tersebut.

Selain hal tersebut, Kabupaten Sorong bersebelahan dengan Kota Sorong, Provinsi Papua Barat dan Kabupaten Tambrauw. Ketiga wilayah tersebut, memiliki sumberdaya alam yang potensial dan akan membuat kegiatan di Pelabuhan Arar menjadi semakin ramai. Di lain pihak kajian ilmiah di Pelabuhan Arar masih sangat minim. Kajian yang dilakukan di wilayah perairan Papua Barat, diantaranya adalah kajian terhadap perikanan anchovy di Selat Kabui, Raja Ampat (Bailey et al., 2008). Rencana pengelolaan taman pulau-pulau kecil dan daerah (TPPKD) Raja Ampat (Mustaghfirin et al., 2012), kajian terhadap ikan-ikan karang di Perairan Papua Barat (Allen dan Erdmann, 2009), survey terhadap biomasa ikan di daerah perlindungan Raja Ampat dari bulan Januari hingga Februari 2013 (Allen, 2013), hutan mangrove di Kalitoko, Teluk Mayalibit, Pulau Waigeo, Kabupaten Raja Ampat, Provinsi Papua Barat (Suhardjono, 2013), pengelolaan sumberdaya karang berbasis integrasi sasi dengan konservasi perairan modern di Raja Ampat (Boli, 2014; Boli et al., 2014a dan b). Strategi Pengembangan Perikanan Pancing Ramah Lingkungan di Kabupaten Raja Ampat Papua Barat (Prayoga, 2014), strategi adaptasi nelayan terhadap penetapan kawasan konservasi perairan daerah di Misool Selatan, KKPD Raja Ampat (Pranata, 
2014), pengamatan suhu permukaan laut Bentang Laut kepala Burung Papua Barat (Program BHS Unipa-CII Sorong, 2014), variasi fitoplankton di Sungai Maralol dan Salawatlol di Pulau Salawati, Kabupaten Sorong, Papua Barat (Setya, 2016). Oleh karena itu dalam rangka mencegah terjadinya kerusakan lingkungan akibat banyaknya limbah yang dihasilkan, maka perlu dilakukan penelitian strategi pengelolaan limbah di Pelabuhan Arar Kabupaten Sorong yang berkelanjutan.

Penelitian yang dilakukan baik di Pelabuhan Kabupaten Sorong maupun di kabupaten lainnya hingga saat ini juga belum ada penelitian tentang pengelolaan limbah pelabuhan. Penelitian yang sudah dilakukan dengan topik pelabuhan yang sudah dilakukan, antara lain adalah evaluasi dampak kebijakan pembangunan Pelabuhan Perikanan Pantai (PPP) Tamperan terhadap perubahan sosial ekonomi masyarakat pesisir sekitar (Anton et al., 2014). Rahmawati et al. (2014) melakukan penelitian tentang Pengembangan Pelabuhan Perikanan Nusantara Brondong, Lamongan dalam rencana penyerapan tenaga kerja masyarakat pesisir. Siahaan (2012) melakukan penelitian tentang Pengembangan Pelabuhan Tanjung Priuk berwawasan lingkungan (ecoport) dalam rangka pengelolaan pesisir terpadu. Diniah et al. (2012) melakukan penelitian tentang Pelayanan pelabuhan perikanan nusantara (PPN) terhadap kebutuhan operasi penangkapan ikan. Guswanto et al. (2012) melakukan penelitian tentang Analisis indeks kinerja pengelola dan indeks kepuasan pengguna di Pelabuhan Perikanan Samudera Nizam Zachman Jakarta. Kohar et al. (2010) melakukan penelitian tentang Analisis program dan kinerja Pelabuhan Perikanan Nusantara (PPN) Pekalongan. Yusuf et al. (2005) melakukan penelitian tentang Dampak Pembangunan Pelabuhan Perikanan Lempasing terhadap Penyerapan Tenaga Kerja dan Pendapatan Masyarakat. Oleh karena itu maka penelitian strategi pengelolaan limbah di Pelabuhan Arar
Kabupaten Sorong perlu dilakukan, agar Pelabuhan Arar menjadi berkelanjutan.

Penelitian ini bertujuan untuk memformulasi strategi pengelolaan limbah di Pelabuhan Arar Kabupaten Sorong yang berkelanjutan. Hasil penelitian ini diharapkan akan menjadi dasar pemerintah daerah untuk mengatasi masalah limbah, sehingga dapat mendorong pertumbuhan ekonomi daerah yang berkelanjutan.

\section{METODA PENELITIAN}

\subsection{Waktu dan Tempat Penelitian}

Penelitian ini dilakukan pada bulan Juni hingga September 2017. Penelitian dilakukan di Pelabuhan Arar, Kabupaten Sorong.

\subsection{Bahan dan Data}

Pada penelitian ini dicari rumusan strategi pengelolaan limbah di Pelabuhan Arar, agar menjadi pelabuhan yang berkelanjutan, sehingga dilakukan formulasi strategi dengan menggunakan analisis hierarki proses (AHP).

Penetapan prioritas strategi dalam AHP dilakukan dengan menangkap secara rasional persepsi dari stakeholder kunci yang ditentukan secara purposive. Dasar pertimbangan penentuan pakar untuk dijadikan responden kriterianya adalah keberadaan, keterjangkauan dan kesediaan responden untuk diwawancarai, mempunyai reputasi, kedudukan dan telah menunjukkan kredibilitasnya sebagai pakar pada bidang yang diteliti minimal tiga tahun, dan telah berpengalaman di bidangnya. Adapun stakeholder yang diwawancara adalah Kepala Dinas Perhubungan Kabupaten Sorong, Kepala Bapeda Kabupaten Sorong, Ketua KEK, Kasubdit Perhubungan, dan pihak perguruan tinggi. Analisis AHP dilakukan konversi faktor-faktor yang tidak terukur (intangible) ke dalam aturan yang biasa, sehingga dapat dibandingkan. 


\subsection{Analisis Data}

Pengolahan data yang dilakukan pada penelitian ini berbasis komputer menggunakan perangkat lunak expert choice 2000. Adapun langkah-langkah dalam analisis data dengan AHP adalah:

1. Mendefinisikan masalah dan menentukan solusi masalah

2. Membuat struktur hirarki yang diawali dengan fokus, dilanjutkan dengan tujuan, kriteria dan alternatif kebijakan pada tingkatan level paling bawah.

3. Membuat matriks perbandingan berpasangan yang menggambarkan pengaruh relatif atau pengaruh setiap elemen terhadap masing-masing tujuan yang setingkat diatasnya, perbandingan berdasarkan judgement dari stakeholder dengan menilai tingkat kepentingan satu elemen dibandingkan dengan elemen lainnya. Mengkuantifikasi data kualitatif pada materi wawancara digunakan nilai skala komparasi $1-9$ berdasarkan skala Saaty

4. Melakukan perbandingan berpasangan. Kegiatan ini dilakukan oleh stakeholder yang berkompeten berdasarkan hasil identifikasi stakeholder.

5. Menguji konsistensinya. Indeks konsistensi menyatakan penyimpangan konsistensi dan menyatakan ukuran tentang konsisten tidaknya suatu penilaian perbandingan berpasangan. Nilai pengukuran konsistensi diperlukan untuk mengetahui konsistensi jawaban dari responden karena akan berpengaruh terhadap keabsahan hasil.

\section{HASIL DAN PEMBAHASAN}

\subsection{Hasil}

Pelabuhan Arar merupakan pelabuhan yang berpotensi untuk berkembang pesat. Hal ini karena di lokasi tersebut sedang dibangun kawasan ekonomi khusus, yang sudah pasti akan memiliki berbagai jenis kegiatan ekonomi. Selain hal tersebut Pelabuhan Arar yang terletak ditengah- tengah antara Kabupaten Sorong, Kota Sorong dan Kabupaten Tambrauw yang kaya akan sumberdaya alamnya juga semakin memperbesar potensi untuk semakin berkembang pesatnya Pelabuhan Arar. Seperti halnya pada pelabuhan yang lain, di Pelabuhan Arar juga dihasilkan sampah dan limbah cair. Dalam melakukan pengelolaan limbah B3 yang dihasilkan, saat ini masih dilakukan dengan sangat sederhana, yakni hanya melakukan penampungan. Sebagai contoh pada limbah B3 yang dihasilkan dari kegiatan bongkar muat kapal, pengelolaannya dilakukan dengan cara menyimpan dalam drum-drum, dan selanjutnya diberikan pada pengumpul berijin. Kondisi seperti saat ini, pengelolaan tersebut, relative sudah masukpada kategori cukup. Namun pada masa yang akan datang, hal tersebut dapat mendatangkan risiko yang potensial dapat menurunkan kualitas air laut di sekitarnya. Pada saat proses menampung tersebut, dapat terjadi ceceren atau bahkan tumpahan ke media air laut dalam jumlah yang semakin dengan berjalannya waktu, diduga akan semakin meningkat. Hal ini mengakibatkan peluang untuk terjadinya pencemaran juga akan semakin meningkat. Oleh karena itu maka perlu dicari strategi pengelolaan Limbah (terutama Limbah B3 dihasilkan dari kapal) di Pelabuhan Arar, Kabupaten Sorong. Penelitian ini, dalam rangka menyusun strategi pengelolaan limbah di Pelabuhan Arar Kabupaten Sorong yang berkelanjutan, digunakan AHP (Analytical Hierarchy Process) (Saxena et al., 1992; Saaty, 1993 dan Marimin, 2009). Berdasarkan hasil pengamatan di lapangan, studi literatur dan hasil diskusi dengan pakar diperoleh lima level hirarki yang terkait secara nyata dan sekaligus akan mempengaruhi strategi pengelolaan limbah di Pelabuhan Arar Kabupaten Sorong yang berkelanjutan, yakni: level I adalah level fokus atau tujuan utama (ultimate goal) yang akan dicapai pada penelitian ini. Adapun tujuan utama pada penelitian ini adalah model pengelolaan limbah di Pelabuhan Arar, 
Kabupaten Sorong; level II adalah level yang merupakan hirarki dari stakeholder yang harus terlibat dalam upaya mencapai tujuan model pengelolaan limbah di Pelabuhan Arar, Kabupaten Sorong. Hasil wawancara dan hasil kajian terkait penelitian ini, ada beberapa stakeholder yang perlu dibandingkan tingkat kepentingannya yakni pemerintah, investor, manajemen perusahaan dan masyarakat; level III adalah level merupakan hirarki dari tujuan yang digunakan untuk mencapai tujuan tersebut dengan dasar pemikiran sejalannya sejalannya kerjasama stakeholder pada hirarki kedua di atas. Beberapa tujuan yang perlu diprioritaskan adalah ekologi, sosial, ekonomi; level IV adalah level yang merupakan hirarki dari faktor yang berpengaruh untuk dapat mencapai tujuan model pengelolaan limbah di Pelabuhan Arar, Kabupaten Sorong. Level ini ada beberapa faktor-faktor yang perlu diprioritaskan sesuai dengan level 3, yakni untuk aspek ekologi adalah limbah B3 dan sampah, ekosistem pesisir, pencemaran tanah dan air, daya dukung lingkungan, tataruang. Pada sector ekonomi adalah PAD, kesejateraan masyarakat (kesra), peluang berusaha, harga IPAL dan TPS serta operasionalnya, serta kelengkapan infrastruktur. Pada aspek sosial adalah budaya lokal, transtibmas, lapangan pekerjaan, koordinasi, konflik masyarakat; level V adalah level yang merupakan hirarki dari identifikasi tujuan yang hendak dicapai dalam pengelolaan limbah di Pelabuhan Arar Kabupaten Sorong yang berkelanjutan. Pada penelitian ini terdapat beberapa tujuan penting yang harus diprioritaskan menyangkut hal tersebut di atas, yakni teknologi zerowaste, habituasi terhadap limbah dan sampah, insentif dan disintensif serta penegakan hukum dan sanksi.

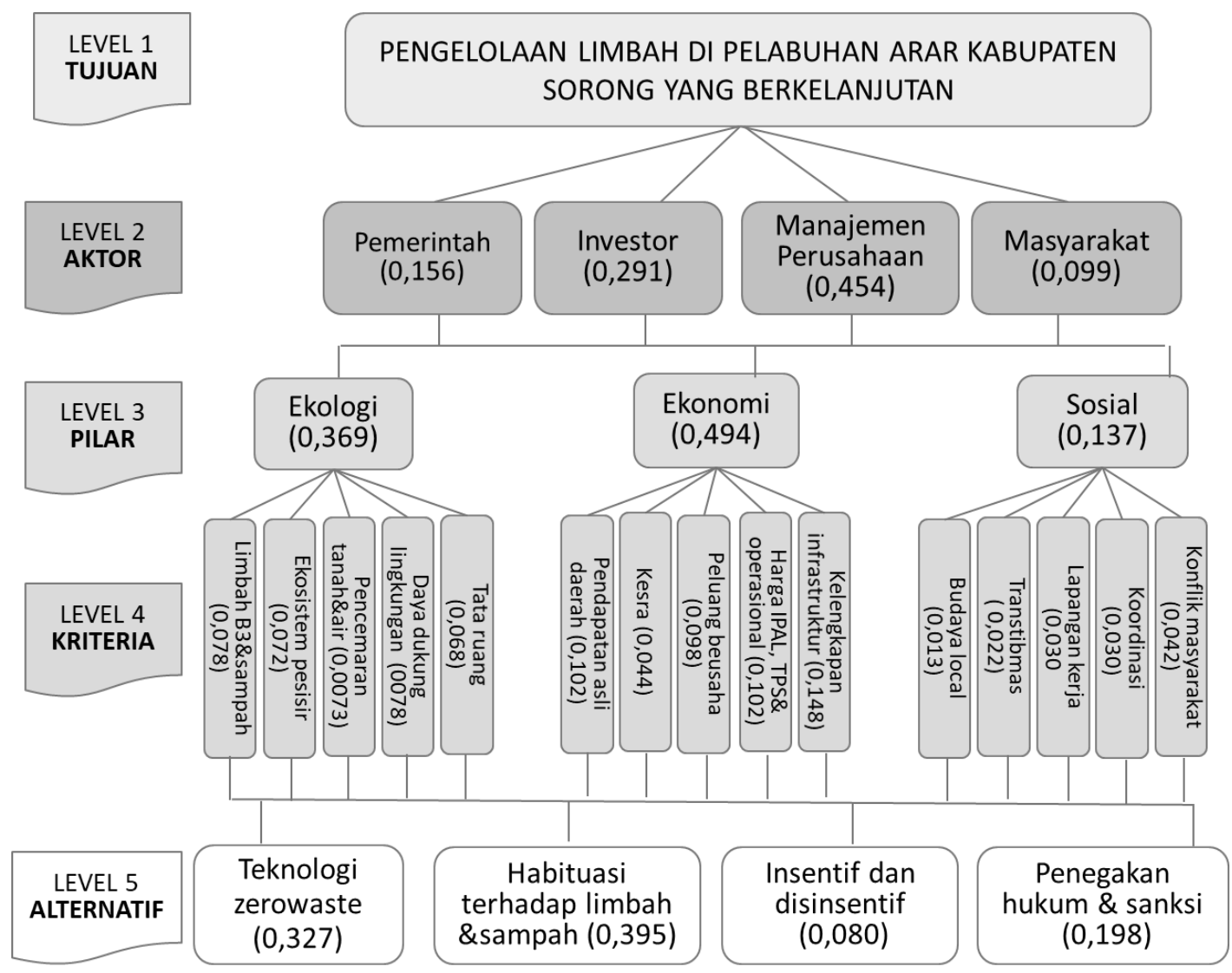

Gambar 11. Bobot faktor-faktor pada setiap level pengelolaan limbah di Pelabuhan Arar Kabupaten Sorong yang berkelanjutan. 
Kelima level di atas bila dituangkan dalam sebuah diagram hirarki pengambilan keputusan pengelolaan limbah di Pelabuhan Arar Kabupaten Sorong yang berkelanjutan seperti yang terlihat pada Gambar 1 . Analisis ini bobot dan prioritas hasil analisis diperoleh dari hasil kombinasi gabungan dari pendapat dan penilaian seluruh stakeholder pada setiap matriks perbandingan berpasangan

\subsection{Pembahasan}

Penelitian ini memperlihatkan bahwa menurut pendapat pakar, pada level dua (aktor), menunjukkan bahwa manajemen perusahaan (bobot 0,454) memegang peran yang paling penting dalam pengelolaan limbah di Pelabuhan Arar Kabupaten Sorong yang berkelanjutan. Kondisi ini menunjukkan bahwa manajemen perusahaan menjadi penentu utama dalam pengelolaan limbah di Pelabuhan Arar Kabupaten Sorong yang berkelanjutan. Prioritas actor kedua adalah investor, dengan bobot 0,291. Hal ini terjadi karena investor merupakan penentu operasional pabrik dan besarnya produksi, selain itu investor juga akan menentukan teknologi mana yang akan digunakan untuk mengolah limbah serta akan menentukan kapan saja dan berapa lama IPAL perusahaan dioperasikan. Kondisi tersebut pada akhirnya akan menjadi penentu utama apakah di wilayah kajian terjadi pencemaran atau tidak.

Prioritas ketiga adalah pemerintah $(0,156)$ dan prioritas keempat adalah masyarakat $(0,099)$. Pada dasarnya aktor pemerintah dan masyarakat dapat berperan sebagai penentu pada tahap implementasi pengelolaan limbah. Kedua aktor ini terlibat dalam proses pengelolaan limbah di Pelabuhan Arar Kabupaten Sorong yang berkelanjutan. Keterlibatan tersebut dimulai dari perencanaan, pelaksanaan, hingga pemantauan dan evaluasi. Hal ini sangat dimungkinkan karena pemerintah memegang otoritas dalam perencanaan dan pembangunan pelabuhan, selain itu juga berperan dalam menjamin kelestarian lingkungan dan sekaligus bertugas untuk meningkatkan kesejahteraan masyarakat.

Level 3, yakni level tujuan pengelolaan lingkungan, prioritas utama yang dipilih oleh stakeholder adalah aspek ekonomi $(0,494)$, prioritas ke dua ekologi $(0,369)$, dan prioritas ke tiga adalah aspek sosial $(0,137)$. Kondisi ini memperlihatkan bahwa dalam pengelolaan limbah di Pelabuhan Arar, stakeholder terkait, umumnya masih lebih mementingkan aspek ekonomi. Prioritas ekologi $(0,369)$ menjadi pilihan kedua stakeholder kunci, mengingat pengelolaan limbah merupakan aspek yang paling harus diperhatikan secara seksama agar kelestarian lingkungan dapat terjamin dengan baik. Aspek sosial menjadi pilihan terakhir para stakeholder. Hal ini diduga karena saat ini yang perlu dikedepankan duluan adalah ekonomi dan lingkungan, sehingga apabila keduanya sudah kuat, maka aspek sosial akan lebih mudah untuk diperbaiki.

Level 4 (kriteria) dari setiap tujuan pengelolaan limbah di Pelabuhan Arar Kabupaten Sorong yang berkelanjutan, diperoleh hasil bahwa untuk mencapai pertumbuhan ekonomi, aspek yang harus diprioritaskan adalah peningkatan PAD $(0,102)$, peningkatan kesejahteraan masyarakat (kesra) $(0,044)$, meningkatkan peluang berusaha $(0,098)$, harga IPAL dan TPS serta operasionalnya yang tinggi $(0,102)$, kelengkapan infrastruktur $(0,148)$. Hal tersebut memperlihatkan bahwa dalam rangka meningkatkan pertumbuhan ekonomi, maka hal yang paling penting adalah melengkapi infrastruktur. Apabila infrastruktur sudah lengkap, maka operasionalisasi Pelabuhan Arar akan dapat dilakukan dengan mudah. Parameter lain yang juga harus diperhatikan adalah) tingginya harga IPAL dan TPS serta ongkos operasionalnya $(0,102)$. Hal ini harus menjadi perhatian lebih, mengingat tingginya biaya pembuatan IPAL dan biaya operasional akan menjadi penghambat dalam melakukan pengelolaan limbah di Pelabuhan Arar Kabupaten Sorong yang berkelanjutan. Oleh 
karena itu maka harus dicari teknologi yang harganya murah dan operasionalnya juga murah. Parameter yang juga sama posisinya karena nilainya sama, adalah peningkatan pendapatan asli daerah (PAD). Hal ini dianggap penting oleh para stakeholder, mengingat tingginya PAD akan membantu pemerintah daerah untuk mewujudkan keinginan mulianya seperti untuk meningkatkan kesejahteraan masyarakat, meningkatkan kelestarian alam dan mewujudkan pembangunan berkelanjutan, yakni pembangunan yang seimbang antara ekologi, ekonomi dan sosial.

Level 5, yakni alternatif pengelolaan limbah di Pelabuhan Arar Kabupaten Sorong yang berkelanjutan, diperoleh hasil bahwa agar pengelolaan limbah di Pelabuhan Arar Kabupaten Sorong menjadi berkelanjutan sebagai berikut. Menurut para stakeholder kunci, alternative kebijakan yang pertama kali harus diadopsi adalah habituasi terhadap limbah dan sampah (0,395). Hal ini mengandung arti bahwa jika ingin agar pengelolaan limbah berjalan dengan baik, maka habituasi atau membiasakan untuk membuang limbah baik cair maupun padat (sampah) secara tepat menjadi penentu utama keberhasilan pengelolaan limbah (Amin, 2009). Hal tersebut sesuai dengan pernyataan Bourdieu (2011), bahwa pada masyarakat yang kodifikasi hukumnya belum terlalu canggih, maka habitus dapat menjadi caracara praktik yang utama di masayarakat tersebut. Harapannya dengan habituasi ini, maka limbah yang dihasilkan tidak dibuang ke lingkungan. Apabila hal ini dapat dilaksanakan dengan baik, maka lingkungan akan terpelihara dengan baik (Harrison, 2000).

Menurut penelitian Quinton (2010), habituasi merupakan proses pembiasaan (pedagogik dan budaya) yang berlangsung pada masyarakat. Selanjutnya dikatakan bahwa pada anak sekolah, habituasi akan terjadi apabila terjadi transfer of knowledge yang membuka pengetahuan siswa tentang makna lingkungan yang bersih dan sehat dilakukan di dalam dan di luar kelas secara incremental. Terkait dengan penelitian ini, habituasi terhadap limbah dan sampah di sini diartikan sebagai pemberian pengetahuan dari guru terhadap limbah dan sampah, yang dilanjutkan di lingkungan keluarganya. Adanya pengetahuan yang diimplementasikan di sekolah dan di lingkungan keluarga, pada akhirnya akan dapat menjadi budaya/ kebiasaan yang dilakukan dalam keseharian (Bourdieu, 2010). Menurut Dumais (2002) pembiasaan mengelola sampah dan limbah di lingkungan sekolah merupakan sosial kapital dalam pembentukan perilaku, karena lingkungan tersebut dapat menjadi rujukan bagi siswa. Berdasarkan hal tersebut, maka habituasi ini, akan membuat siswa selalu melakukan pengelolaan terhadap limbah dan sampah yang dihasilkan pada keseharian. Kebiasaan mengelola limbah dan sampah ini akan muncul dari alam bawah sadarnya, sehingga menjadi kebiasaan yang melekat pada dirinya. Apabila mengelola limbah dan sampah ini menjadi habituasi, maka bukan hanya lingkungan sekolah dan rumah yang bersih, namun lingkungan lain, termasuk di dalamnya pelabuhan Arar, akan menjadi lingkungan yang bersih dan sehat, dan terhindar dari masalah limbah dan sampah.

Alternatif kedua yang harus diperhatikan setelah habituasi adalah mengimplementasikan teknologi zerowaste. Pada alternative ini, pengelolaan limbah dan sampah yang ada di Pelabuhan Arar, hendaknya diarahkan pada pemanfaatan limbah dan sampah untuk dijadikan bahan guna kegiatan lainnya, sehingga akan tercipta proses zero waste, seperti yang diinginkan oleh Agenda 21. Terkait hal tersebut, maka hal yang juga tidak kalah pentingnya adalah mencari teknologi-teknologi pengolahan limbah yang mengarah pada zerowaste yang efisien dan efektif. Pada teknologi zerowaste, misalnya untuk limbah cair, baik berupa limbah domestik atau limbah B3 dari proses-proses kegiatan di Pelabuhan Arar, setelah dilakukan pengolahan dalam instalasi pengolah air limbah, hasil pengolahannya dimanfaat- 
kan untuk kepentingan lain, sehingga limbah sisa yang harus dibuang ke lingkungan menjadi sangat minim.

Terkait dangan sampah (limbah padat), pada teknologi zerowaste, maka semua kegiatan di Pelabuhan Arar tidak boleh langsung membuang ke lingkungan, namun sampah tersebut harus dimanfaatkan kembali untuk berbagai kepentingan lain. Sampah organik mudah urai, dapat diolah menjadi pupuk organik, yang selanjutnya dimanfaatkan untuk membuat ruang terbuka hijau (RTH). Sampah yang sulit atau yang sangat sulit urai, dipilah terlebh dahulu, dan selanjutnya dimanfaatkan kembali (reuse atau recycle). Namun apabila tidak bisa digunakan lagi, maka sampah dibuang ke TPA. Namun adanya reuse dan recycle ini, maka limbah padat yang dibawa ke TPA menjadi sangat sedikit (minimal). Agar kondisi tersebut dapat tercapai dengan baik, menurut Morrisey dan Browne (2004) maka aspek sosial harus dapat diintegrasikan pada penerapan system pengelolaan limbah tersebut.

Alternatif ke tiga yang harus diperhatikan adalah penegakan hukum dan sanksi. Dasarnya Indonesia sudah memiliki berbagai kebijakan, aturan dan SOP yang ditujukan agar limbah dan sampah tidak mencemari lingkungan. Namun sayangnya kebijakan, aturan dan SOP tersebut relatif belum dapat menanggulangi terjadinya pencemaran lingkungan. Kondisi ini umumnya terjadi karena masih maraknya pelanggaran pada berbagai hal. Pelanggaran ini sendiri pada umumnya terjadi karena belum ketatnya penegakan hukum dan sanksi yang diberikan kepada yang melanggar (Riani, 2012). Selain hal tersebut menurut Riani (2012) juga karena orientasi dari penegakan hokum dan sanksi tersebut umumnya masih berupa sanksi dalam bentuk uang yang cukup tinggi, sehingga memungkinkan pelanggar dan petugas samasama mencari sama-sama untung. Oleh karena itu maka hal tersebut harus dihindari sebaik mungkin, sehingga penegakan hukum dan sanksi dapat dilaksanakan secara tegas dan mengikat tanpa pandang bulu, sehingga pelanggaran dalam pengelolaan limbah dan sampah dapat diminimalkan. Terkait hal tersebut, maka hal yang tidak kalah pentingnya agar terjadi penegakan hukum dan sanksi adalah menjaga ketaatan dan kedisiplinan dari aparat penegak hukum itu sendiri.

Alternatif ke empat yang juga harus mendapat perhatian dari pemerintah adalah mengembangkan instrumen yang insentifdisinsentif dalam hal ini pemerintah bukan memberikan hukuman berupa denda uang kepada yang melanggar untuk mengelola limbahnya, misalnya diberikan dalam bentuk sanksi dalam bentuk efek jera (Riani, 2012). Bagi institusi yang melaksanakan pengelolaan limbah dan sampahnya dengan baik dan benar, perlu diberi penghargaan dalam bentuk dibebaskan dari kewajiban tertentu, misalnya dari pajak yang seharusnya dikenakan pada institusi tersebut (Riani, 2012).

\section{KESIMPULAN}

Terdapat tiga strategi utama yang harus dilakukan pada pengelolaan limbah di Pelabuhan Arar Kabupaten Sorong secara berkelanjutan, yakni: harus membiasakan masyarakat (habituasi) untuk melakukan pengolahan limbah dan sampah menjadi satu kebiasaan dan budaya dalam keseharian, mencari dan menerapkan teknologi zerowaste, dan melakukan penegakan hukum.

\section{DAFTAR PUSTAKA}

Allen, M. 2013. A rapid fish biomassa survey of sites in the Raja Ampat Marine Protected Area Network in JanuaryFebruary 2013. Narrative report to Conservation International Indonesia. Indonesia. 21p.

Allen, G.R. and M.V. Erdmann. 2009. Reef fishes of the Bird ${ }^{\text {ee }}$ Head Peninsula, 
West Papua, Indonesia. Check List, 5:587-628.

Amin, N. 2009. Reducing emissions from private cars: incentive measures for behavioural change. United Nations Environment Programme. 172p.

Anton, M., Mardiyono, and WY. Prasetya 2014. Evaluasi dampak kebijakan pembangunan pelabuhan perikanan pantai (PPP) tamperan terhadap perubahan sosial ekonomi masyarakat pesisir sekitar (studi kasus pada PPP Tamperan Kab. Pacitan). J. Administr Publ., 2(11):1010-1015.

Bailey, M., C. Rotinsulu, and U.R. Sumaila. 2008. The migrant anchovy fishery in Kabui Bay, Raja Ampat, Indonesia: catch, profitability, and income distribution. Marine Policy, 32:483488.

Boli, P. 2014. Pengelolaan sumberdaya karang berbasis integrasi sasi dengan konservasi perairan modern di Raja Ampat. Disertasi. Sekolah Pascasarjana IPB. Bogor. 131hlm.

Boli, P., F. Yulianda, A. Damar, D. Soedharma, and R. Kinseng 2014a. Benefits of sasi for conservation of marine resources in Raja Ampat, Papua. JMHT., 20(2):131-139.

Boli, P., F. Yulianda, A. Damar, D. Soedharma, and R. Kinseng 2014b. Integration of marine resources management based customary into modern conservation management in Raja Ampat, Indonesia. IJSBAR, 13(2):280-291.

Bourdieu, P. 2010. Arena produksi kultural: sebuah kajian sosiologi budaya. Adhi Krisna (penterjemah) The field of cultural production: Essays on art and literature. Yogyakarta. 396p.

Bourdieu, P. 2011. Choses dites, uraian dan pemikiran. Adhi Krisna (penterjemah). Choses dites. Yogyakarta. 270p.

Diniah, M.P. Sobari, dan D. Seftian. 2012. Pelayanan pelabuhan perikanan nusantara (PPN) terhadap kebutuhan operasi penangkapan ikan. $J$. Kebijakan Sosial Ekonomi Kelautan dan Perikanan, 2(1):41-49.

Dumais, S.A. 2002. Cultural capital, gender, and school success: The role of habitus. Sociology of Education, 75(1): 44-68.

Guswanto, B., I. Gumilar, dan H. Hamdani. 2012. Analisis indeks kinerja pengelola dan indeks kepuasan pengguna di Pelabuhan Perikanan Samudera Nizam Zachman Jakarta. $J$. Perikanan dan Kelautan, 3(4):151163.

Harrison, D. 2000. Design for sustainability is a reality, in exploring design and innovation. Brunel University. London. 107p.

Kohar, A., A. Suherman, dan M.A. Wijayanto. 2010. Analisis program dan kinerja Pelabuhan Perikanan Nusantara (PPN) Pekalongan. Semarang. J. Saintek Perikanan. 7(1):32-38.

Marimin. 2009. Teori dan aplikasi sistem pakar. IPB Press. Bogor. 324hlm.

Morrisey, A. and J. Browne. 2004. A methodology for community based waste management decisions. The $J$. of Solid Waste Technology and Management, 30(3):170-182.

Mustaghfirin, M.P. Urbinas, F.Urbasa, M.V. Erdmann, S. Mangubhai, M. Fox, M. Khazali, L. Rumetna, A. Nebore, K. Thebu, D. Setyawan, M. Mongdong, A. Djunaidi, K. Wamafma, J. Maturbongs, Purwanto, Muhajir, N.I. Hidayat, dan S. Sabonnama. 2012. Rencana pengelolaan taman pulaupulau kecil dan daerah (TPPKD) Raja Ampat: data \& analisis. buku 2. unit pelaksana teknis daerah TPPKD Raja Ampat. Dinas Kelautan dan Perikanan Pemerintah Daerah Kabupaten Raja Ampat. Waisai. 164hlm.

Pranata, R.T.H. 2014. Strategi adaptasi nelayan terhadap penetapan kawasan 
konservasi perairan daerah di Misool Selatan, KKPD Raja Ampat. Thesis Sekolah Pascasarjana. IPB. 113hlm.

Program BHS Unipa-CII Sorong 2014. Kumpulan data pengamatan suhu permukaan laut Bentang Laut kepala Burung Papua Barat. BHS Unipa-CII. Sorong. 98hlm.

Quinton, A. 2010. The foundations of knowledge. Dalam: Dearden et al. (eds). Education and the development of reason. London: Routledge \& Kegan Paul. 205-226pp.

Rahmawati, W., A. Suryono, dan Siswidiyanto. 2014. Pengembangan pelabuhan perikanan dalam rencana penyerapan tenaga kerja masyarakat pesisir (Studi pada Kantor Pelabuhan Perikanan Nusantara Brondong Kabupaten Lamongan). J. Administr Publ. 2(2):367-373.

Riani, E. 2009. Small size green mussel (Perna viridis) as "vacuum cleaner" for liquid waste. J. Alami, Air, Lahan, Lingkungan dan Mitigasi Bencana, 14(3): $24-30$.

Riani, E. 2010. Mercury (Hg) contamination in the body organ of common ponyfish (Leiognathusequulus) in Ancol Waters, Jakarta Bay. J. Teknol. Lingkungan. Agency for the Assessment and Application of Technology. 11(2):313-322.

Riani, E. 2011. Reproductive disorder due to heavy metal contamination in green mussels (Perna viridis) cultured in Muara Kamal Waters, Jakarta Bay. $J$. Moluska Indonesia, 2(2):67-74.

Riani, E. 2012. Climate change and aquatic biota life (The impact on bioaccumulation of toxic and hazardous materials \& reproduction). IPB Press. Bogor. 320p.

Riani, E., H.S. Johari, and M.R. Cordova. 2017a. Kontaminasi $\mathrm{Pb}$ dan $\mathrm{Cd}$ pada ikan bandeng Chanos chanos yang dibudidaya di Kepulauan Seribu,
Jakarta. J. Ilmu dan Teknologi Kelautan Tropis, 9(1):235-246.

Riani, E., H.S. Johari, and M.R. Cordova. 2017b. Bioakumulasi logam berat kadmium dan timbal pada kerang kapak-kapak (Pinna muricata) di Kepulauan Seribu. JPHPI 20(1): 131142.

Riani, E., M.R.Cordova, and Z. Arifin. 2017c. A potential of green mussel (Perna viridis) as a bioacumulator in heavy metal polluted sea. International Conference On Advanced Technology in Waste Water and Waste anagement for Extractive Industries. Exceed. DAAD. Aston Hotel, Nusa Dua Bali October 23-25, 2017. 8p.

Saaty, T.L. 1993. Pengambilan keputusan bagi para pemimpin proses hierarki analitik untuk pengambilan keputusan dalam situasi yang kompleks. Liana Setiona, L. (penterjemah). PT. Pustaka Binaman Pressindo dan PT. Gramedia. Jakarta. 270p.

Saxena, J.P., Sushil, and P. Vrat. 1992. Hierarchy and clasification of program plan elements using interpretative structural modeling: A case study of energy conservation in the Indian cement industry. Systemic practice and Action Research, 5(6):651-670.

Setya, P.S. 2016. Variasi fitoplankton di Sungai Maralol dan Salawatlol di Pulau Salawati, Kabupaten Sorong, Papua Barat. Thesis. Sekolah Pascasarjana. IPB. 33p.

Suhardjono. 2013. Hutan mangrove di Kalitoko, Teluk Mayalibit, Pulau Waigeo, Kabupaten Raja Ampat, Provinsi Papua Barat. J. Biologi Indonesia. 9(1):1-11.

Yusuf H, K. Moedikdjo, M.S. Saeni, dan L.I. Nasution. 2005. Dampak pembangunan pelabuhan perikanan terhadap penyerapan tenaga kerja dan pendapatan masyarakat (studi kasus di 
pelabuhan perikanan Lempasing, Diterima

: 12 Desember 2017

Bandar Lampung). Bul Ekon Perik., Direview : 30 Desember 2017 6(1):57-64 
